\title{
Development of an Electronic Manometer for Intrapleural Pressure Monitoring
}

\author{
Rafał Krenke ${ }^{a}$ Maciej Guć ${ }^{b} \quad$ Elżbieta Magdalena Grabczak ${ }^{a}$ \\ Marcin Michnikowski ${ }^{b}$ Krzysztof Jakub Pałko ${ }^{\text {b }}$ Ryszarda Chazan ${ }^{\text {a }}$ \\ Tomasz Gólczewski ${ }^{\text {b }}$ \\ a Department of Internal Medicine, Pneumonology and Allergology, Medical University of Warsaw, and \\ ${ }^{\mathrm{b}}$ Institute of Biocybernetics and Biomedical Engineering, Polish Academy of Sciences, Warsaw, Poland
}

\section{Key Words}

Electronic manometer $\cdot$ Intrapleural pressure $\cdot$ Pleural

effusion - Pleural manometry $\cdot$ Thoracentesis

\begin{abstract}
Background: Measurement of intrapleural pressure is useful during various pleural procedures. However, a pleural manometer is rarely available. Objectives: The aim of this study was to (1) construct an electronic pleural manometer, (2) assess the accuracy of the measurements done with the new device, (3) calculate the costs of the manometer construction and (4) perform an initial evaluation of the device in a clinical setting. Methods: Only widely accessible elements were used to construct the device. A vascular pressure transducer was used to transform pressure into an electronic signal. Reliability of the measurements was evaluated in a laboratory setting in a prospective, single-blind manner by comparing the results with those measured by a water manometer. Functionality of the device was assessed during therapeutic thoracentesis. The cost of the new pleural manometer was calculated. Results: We built a small, portable device which can precisely measure intrapleural pressure. The measurement results showed very high agreement with those regis-
\end{abstract}

tered with a water manometer $(r=0.999 ; p<0.001)$. The initial evaluation of the electronic manometer during therapeutic thoracentesis showed it was easy to use. The total time needed for 6 measurements after withdrawal of different volumes of pleural fluid in 1 patient did not exceed $6 \mathrm{~min}$. The total cost of the device was calculated to be $<2,000$ EUR. Conclusions: In the face of very limited offer of commercially available pleural manometers, it is possible to successfully construct a self-made, reliable, electronic pleural manometer at modest costs. The device is easy to use and enables data display and storage in the personal computer.

Copyright $\odot 2011$ S. Karger AG, Basel

\section{Introduction}

Measurement of intrapleural pressure has been shown to be useful in various pleural procedures. In the preantibiotic era, pleural manometry was commonly used in collapse therapy of tuberculosis [1]. Then the procedure was abandoned by the majority of practicing pulmonologists and applied almost exclusively during artificial pneumothorax creation before medical thoracoscopy [2, 3]. Currently, interest in pleural pressure measurement

\section{KARGER}

Fax +4161306 1234

E-Mail karger@karger.ch

www.karger.com (c) $2011 \mathrm{~S}$. Karger AG, Basel

$0025-7931 / 11 / 0824-0377 \$ 38.00 / 0$

Accessible online at:

www.karger.com/res
Rafal Krenke, MD, PhD

Department of Internal Medicine, Pneumonology and Allergology

Medical University of Warsaw, Banacha la

PL-02-097 Warsaw (Poland)

Tel. +48 22599 2562, E-Mail rafalkrenke@interia.pl 
and monitoring seems to be restored. Pleural manometry is used for studying various pathophysiological aspects of thoracentesis and pleural fluid removal, including the safety of high-volume thoracentesis, immediate detection of an unexpandable lung, as well as differentiation between trapped lung and lung entrapment [4-8]. Some studies also suggested its usefulness in the treatment of spontaneous pneumothorax $[9,10]$. The development of new tools and devices for medical thoracoscopy $[11,12]$ as well as new evidence for the safety of thoracoscopic large-particle talc poudrage [13] expand clinical applications of this procedure in patients with pleural effusion. Pleural manometry may become an important tool in pre-thoracoscopic assessment and in the selection of the optimal therapeutic option.

In the early studies, water manometers (simple, Ushaped tube) were mainly used. However, due to the physical characteristics of water resulting in a relatively high inertia and flow resistance, the precise registration of intrapleural pressure changes during the respiratory cycle was difficult [14-16]. Therefore, only an approximate, mean intrapleural pressure was manually calculated $[4$, $5,8]$. Introduction of overdamped manometers allowed to decrease water oscillation and enabled direct reading of mean pleural pressure. Nevertheless, these manometers also show some drawbacks which include significant disturbances in data registration related to rapid changes in intrapleural pressure (e.g. during cough) as well as inability of data storage and analysis. These drawbacks were eliminated by the introduction of electronic devices. Electronic manometers use a pressure transducer which changes pressure into an electronic signal. This signal can be further analyzed by a signal conditioner and can be displayed and stored in a data acquisition system. Attempts have been made to adapt hemodynamic monitors for displaying pleural pressure, but these monitors require special calibration and recalculation of pressure values from $\mathrm{mm} \mathrm{Hg}$ to $\mathrm{cm}_{2} \mathrm{O}$ [14-16].

Planning our project on evaluating the role of pleural pressure measurements in the prediction of the lung reexpansion ability in patients with various types of pleural effusion, we faced the problem of finding a manometer which would be dedicated specifically for pleural pressure measurement. The offer of commercial pleural manometers was very limited and none of these manometers was easily available in our country. Under these circumstances, we decided to construct a simple and user-friendly electronic pleural manometer based on commercially available medical pressure transducers.

\section{Objectives}

The aims of our study were:

(1) To construct an electronic device which could transform, read and analyze pleural hydrostatic pressure as well as store and display data using simple and widely accessible elements, e.g. pressure transducers used for blood pressure measurements and a personal computer (desktop computer or laptop).

(2) To evaluate the accuracy of the measurements performed with the new device by comparing the results with those obtained with a water manometer.

(3) To calculate the costs of (1) pleural manometer construction and (2) the procedure of intrapleural pressure measurements.

(4) To check the functionality of the manometer by its practical use during thoracentesis and pleural fluid removal.

\section{Methods}

The study was approved by the institutional review board. Consistently with the above-presented aims, the study was performed in the following three phases: construction of the manometer (phase 1), evaluation of measurement accuracy in the mechanical model (phase 2) and preliminary assessment of the functionality of the manometer when used during therapeutic thoracentesis in patients with pleural effusion (phase 3).

Phase 1

We used a vascular pressure transducer (Codan, Forstinning, Germany) to transform pressure to an electric signal measured by the electronic manometer. The results were displayed on the builtin numerical display and also transferred to and displayed on the PC (laptop). The electronic manometer (fig. 1a) consisted of a stabilized current source feeding the bridge of the pressure transducer, a detector and an amplifier of the electric (voltage) signal from the bridge, filters and amplifiers of the electric signal, an LCD display and an analog-to-digital (A/D) converter with USB 2.0 interface for $\mathrm{PC}$ connection. The minimal $\mathrm{PC}$ requirements were as follows: Windows XP + Service Pack 2, 256 MB RAM, processor Pentium III or Celeron $600 \mathrm{MHz}$. The program for pressure value display and recording was created using a LabView platform, version 8.5 (National Instruments, Austin, Tex., USA). The main components used to build the manometer and their functions are presented in table 1.

\section{Phase 2}

Measurement accuracy was assessed by comparing the results obtained with the newly developed device with the respective measurements registered with a water manometer. The set for pressure measurements was installed as presented in figure $1 \mathrm{~b}$. The water manometer was a U-shaped tube (internal diameter 3.0 $\mathrm{mm}$ ) fixed to a measuring scale ranging from +40 to $-40 \mathrm{~cm}$. A 3 -way stopcock was used to connect the $U$ tube with the pressure 


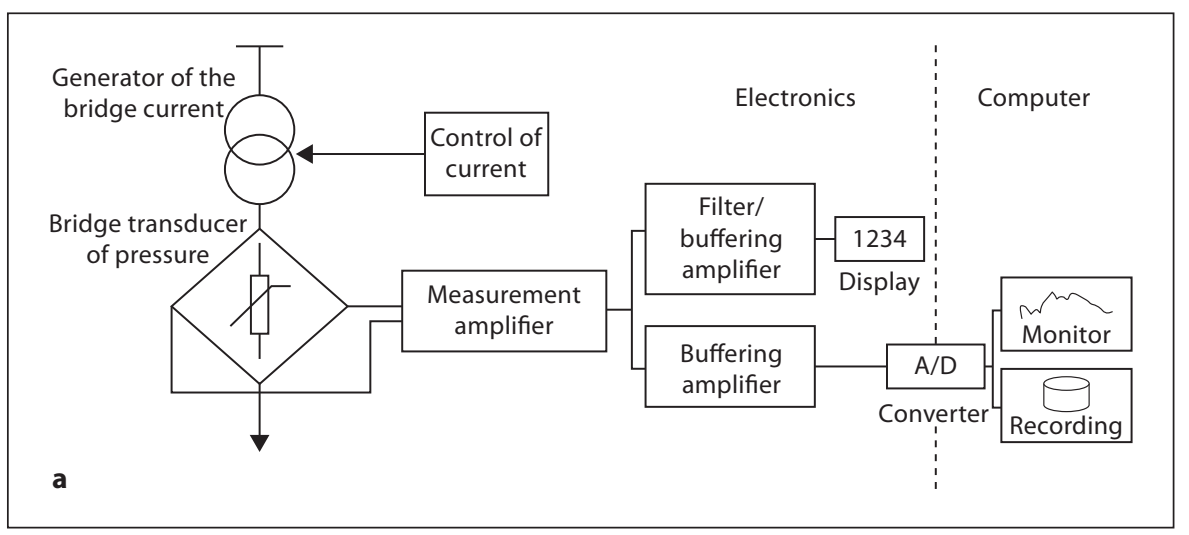

Fig. 1. a Scheme of the electronic manometer. b Setup to compare the electronic manometer with the water manometer.

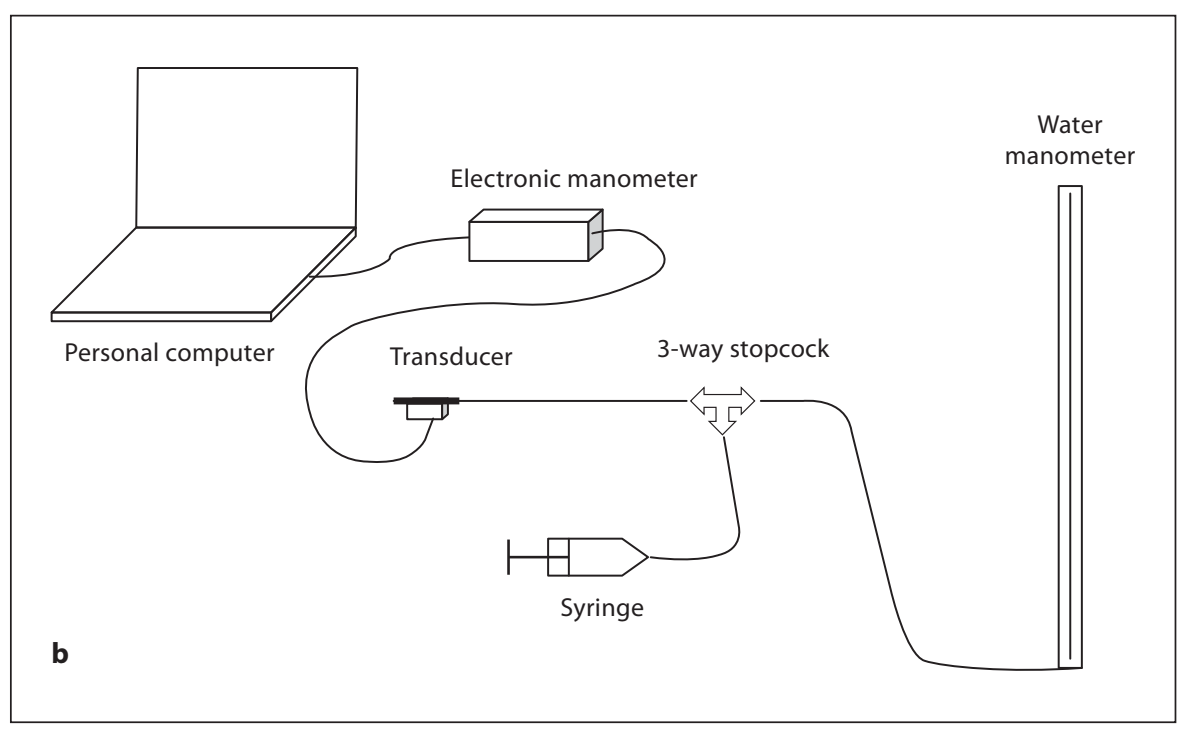

transducer and a syringe filled with water. The use of the syringe allowed to change the hydrostatic pressure during the measurements. Prior to the procedure, the system was carefully purged of air with water and the electronic pressure signal was calibrated against the water standard. Then, 20 pre-prepared lots with numbers between -40 and +40 were subsequently chosen in a random manner by one of the investigators (E.M.G.) and the appropriate pressure value (as indicated by the number) was positioned on the water manometer by the second investigator (R.K.). The third investigator (M.G.), who measured the pressure with the electronic device, was blinded to both the randomly chosen number and the value of the positioned hydrostatic pressure on the water manometer. The pressure was registered for $15 \mathrm{~s}$. The measurements were recorded via the $A / D$ converter with a sampling rate of $100 \mathrm{~Hz}$ and the mean value was taken in time intervals of $2 \mathrm{~s}$. The procedure (20 measurements at different pressure points of hydrostatic pressure) was repeated 7 times, using two different pressure transducers. Then, the pressure values measured with the electronic manometer were compared with those set on the water manometer. The recorded data were analyzed using both linear regression analysis and the Bland-Altman procedure, which is commonly used for comparing two measurement devices.
The costs of all elements used to build the manometer were calculated (in EUR). Workload was separately calculated and expressed in man-hours.

\section{Phase 3}

Having completed the construction and accuracy assessment phases, we used the manometer in a clinical setting for measuring intrapleural pressure during therapeutic thoracentesis performed in 7 patients with pleural effusion. Pressure transducer and electronic manometer were connected via a 3-way stopcock to a small-bore catheter inserted into the pleural cavity. The vertical reference point for a pressure of 0 was arbitrarily defined at the level at which the catheter was inserted into the chest. Pleural fluid was aspirated with a $60-\mathrm{ml}$ syringe. The first measurement was performed directly after pleural catheter insertion and then repeated after withdrawal of every $250 \mathrm{ml}$ of pleural fluid up to a total volume of $1,000 \mathrm{ml}$. When the volume of pleural fluid withdrawn exceeded 1,000 $\mathrm{ml}$, the measurements were performed every $100 \mathrm{ml}$ of pleural fluid withdrawn. The total time of all measurements was calculated and compared to the total procedure time. 
Table 1. Characteristics of the main elements used to construct an electronic pleural manometer

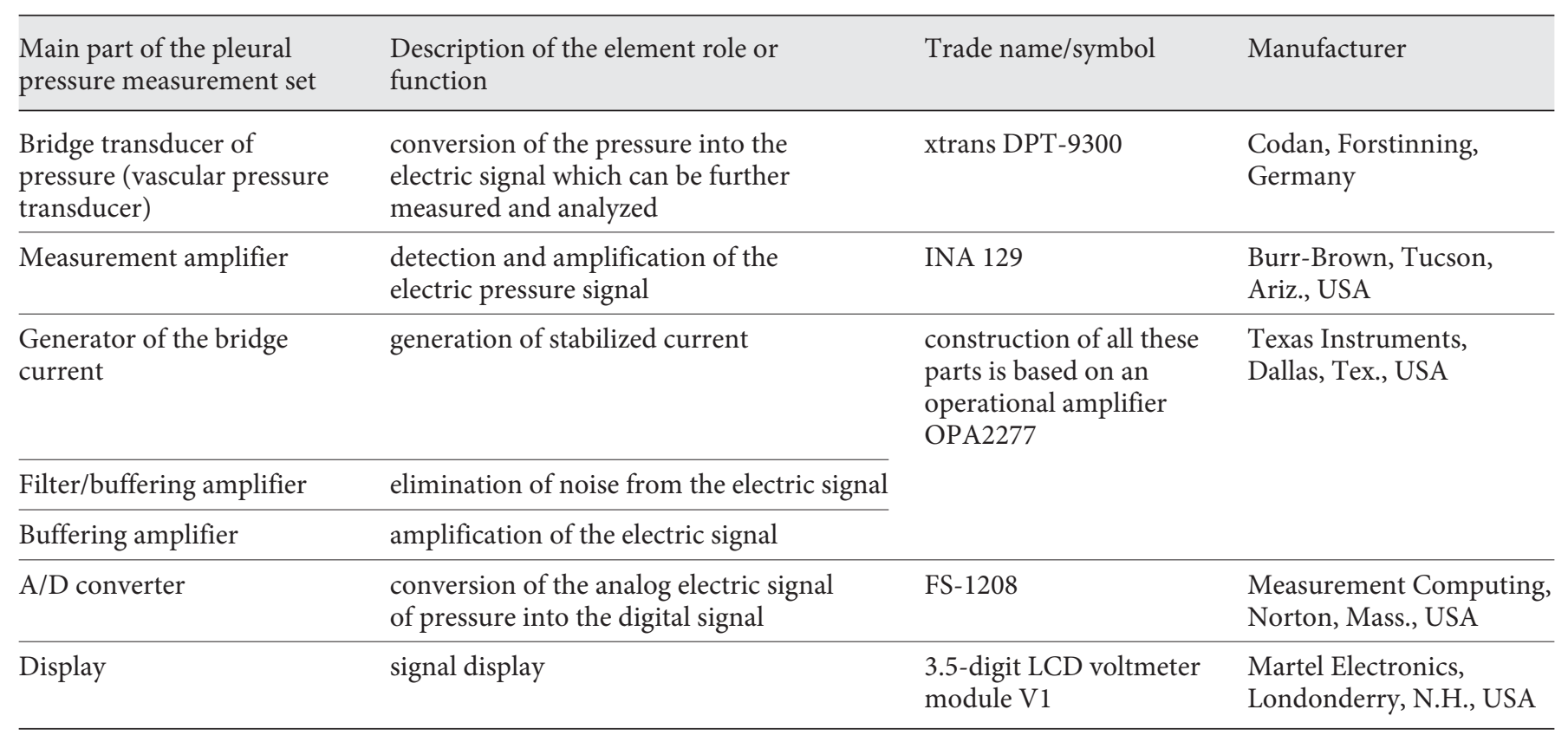

Table 2. The results of the analysis of 7 measurement sets (mechanical model)

\begin{tabular}{|c|c|c|c|c|c|c|c|c|}
\hline \multirow[t]{2}{*}{ No. } & \multirow{2}{*}{\multicolumn{2}{|c|}{$\frac{\text { Linear regression }}{\text { regression line } \mathrm{ax}+\mathrm{b}}$}} & \multicolumn{6}{|c|}{ Bland-Altman method } \\
\hline & & & \multicolumn{2}{|c|}{ CI for differences } & \multicolumn{2}{|c|}{ CI for upper limit of agreement } & \multicolumn{2}{|c|}{ CI for lower limit of agreement } \\
\hline 1 & 0.99957 & -0.04744 & 0.02408 & -0.1190 & 0.10296 & 0.29352 & -0.38848 & -0.19793 \\
\hline 2 & 0.99961 & -0.43937 & -0.36695 & -0.5118 & -0.2871 & -0.09424 & -0.78451 & -0.59164 \\
\hline 5 & 1.0094 & 0.19357 & 0.31631 & 0.07083 & 0.45162 & 0.77846 & -0.39132 & -0.06448 \\
\hline 6 & 1.0095 & 0.32723 & 0.44247 & 0.21199 & 0.56951 & 0.87639 & -0.22193 & 0.08494 \\
\hline 7 & 1.0001 & 0.23903 & 0.49699 & -0.01924 & 0.78154 & 1.4689 & -0.99111 & -0.30378 \\
\hline
\end{tabular}

\section{Results}

We constructed a small, portable, electronic manometer which allows to measure fluid pressure, to display its values as well as to store the measurement results. The dimensions of the device are: $9.0 \times 24.5 \times 15.0 \mathrm{~cm}$. The power supplies consist of two sets (one is required for work and a second for 'hot swap') of 4 rechargeable $\mathrm{Ni}$ $\mathrm{MH}$ batteries (2,500 mAh, 1.2 V, AA size). The sampling rate of $100 \mathrm{~Hz}$ and registration of mean values of $10 \mathrm{con}$ secutive measurements performed in 0.1-second inter- vals allow to detect even small or rapid pressure changes. Intrapleural pressure is presented in $\mathrm{cm}_{2} \mathrm{O}$. Since the numerical display is an integral part of the manometer, monitoring real-time intrapleural pressure does not necessarily require a PC (laptop). Connection to a notebook is only necessary to store data or show intrapleural pressure changes as a function of time (fig. 1b, 2).

All experimental measurements were done with laboratory equipment only and without involvement of any biological elements. The comparison of measurements performed with the electronic and water manometer un- 
Fig. 2. a Exemplary recording of the pleural pressure during pleural fluid removal. The pressure was measured at intervals depending on the fluid volume removed (marked with grey arrows). The volume of pleural fluid removed is presented below the arrows. $\mathbf{b}$ Record of the first measurement of intrapleural pressure (magnification).
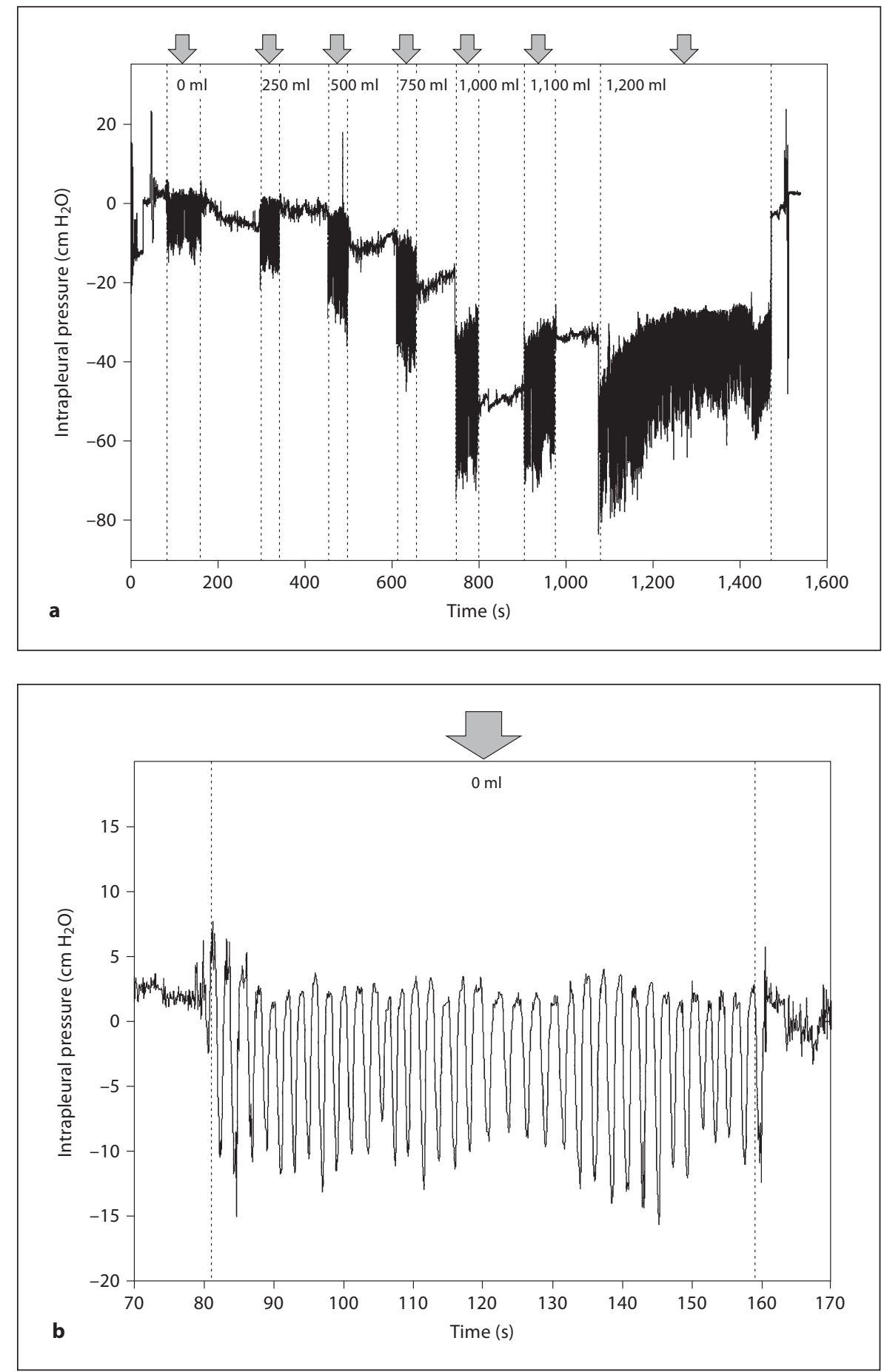

der steady-state conditions and in pressure range from -40 up to $+40 \mathrm{~cm} \mathrm{H}_{2} \mathrm{O}$ showed very good agreement of readings. The results of the analysis of 7 measurement sets are presented in table 2. Examples of linear regression and Bland-Altman plots for measurement set 1 are shown in figure 3. Precision of the measurements was very high and the $95 \%$ confidence interval (CI) for agreement was narrow, ranging from -0.3 to $+0.2 \mathrm{~cm} \mathrm{H}_{2} \mathrm{O}$. We observed also high values of Pearson's correlation coefficient $(\mathrm{r}=$ 0.999; $\mathrm{p}<0.001$ ).

We managed to build the manometer with the use of simple and widely accessible elements. Significant costs 
Table 3. Characteristics of the patients who underwent therapeutic thoracentesis with pleural pressure measurements

\begin{tabular}{|c|c|c|c|c|c|c|c|}
\hline $\begin{array}{l}\text { Patient } \\
\text { No. }\end{array}$ & $\begin{array}{l}\text { Sex } \\
\text { (age, years) }\end{array}$ & $\begin{array}{l}\text { Side } \\
\text { of PE }\end{array}$ & $\begin{array}{l}\text { PE volume on CR } \\
\text { (fraction of hemithorax } \\
\text { occupied by PE) }\end{array}$ & Cause of PE & $\begin{array}{l}\text { Volume of } \\
\text { PE withdrawn } \\
\text { ml }\end{array}$ & $\begin{array}{l}\text { Initial } \\
\text { IPIP/IPEP } \\
\mathrm{cm} \mathrm{H}_{2} \mathrm{O}\end{array}$ & $\begin{array}{l}\text { Final } \\
\text { IPIP/IPEP } \\
\mathrm{cm} \mathrm{H}_{2} \mathrm{O}\end{array}$ \\
\hline 2 & $\mathrm{~F}(61)$ & $\mathrm{L}$ & $>2 / 3$ & MPE (breast) & 1,700 & $-8 / 5$ & $-25 /-8$ \\
\hline 3 & $\mathrm{~F}(81)$ & $\mathrm{R}$ & entire hemithorax & MPE (ovary) & 2,000 & $-8 / 4$ & $-25 /-10$ \\
\hline 4 & $\mathrm{~F}(74)$ & $\mathrm{L}$ & $2 / 3$ & MPE (colon) & 1,630 & $-3 / 4$ & $-26 /-12$ \\
\hline 6 & $\mathrm{~F}(58)$ & $\mathrm{R}$ & $1 / 3-1 / 2$ & MPE (breast) & 1,600 & $2 / 7$ & $-19 /-2$ \\
\hline 7 & $F(66)$ & $\mathrm{R}$ & $1 / 2$ & MPE (NSCLC) & 1,250 & $-2 / 3$ & $-12 /-7$ \\
\hline
\end{tabular}

$\mathrm{PE}=$ Pleural effusion; $\mathrm{CR}=$ chest radiograph; $\mathrm{MPE}=$ malignant pleural effusion (primary tumor site) $\mathrm{CABG}=$ coronary artery bypass grafting; IPIP = intrapleural inspiratory pressure; IPEP = intrapleural expiratory pressure.

related to workload were estimated at approximately 80 man-hours. The total cost of the elements used to construct the device is, however, relatively low and was estimated at $<500$ EUR in the laboratory version (plus the cost of the PC). The main costs included a converter (270 EUR) and a display (20 EUR). We believe this cost can be significantly reduced when modifying the project for small-series production. The cost of pleural pressure measurement in our patient was limited to the cost of a single-use pressure transducer (14 EUR).

Basic patient characteristics, the volume of pleural fluid removed as well as the results of pleural pressure measurements in the 7 patients who underwent therapeutic thoracentesis are shown in table 3. The pattern of intrapleural pressure changes registered in all these patients was similar. To exemplify this pattern, the results of measurements performed during the therapeutic thoracentesis in patient 1 are described below and presented in figure 2 . The first measurement was performed after pleural catheter insertion and then repeated after removal of 250 , $500,750,1,000,1,100$ and $1,200 \mathrm{ml}$ of pleural fluid. The initial intrapleural pressure wavered between -15 and +5 $\mathrm{cm} \mathrm{H}_{2} \mathrm{O}$ and progressively decreased with increasing volume of pleural fluid aspirated. The total pleural effusion volume withdrawn was $1,200 \mathrm{ml}$, and the lowest intrapleural pressure measured after the termination of pleural fluid removal was $-87 \mathrm{~cm}_{2} \mathrm{O}$, with a maximal amplitude of $40 \mathrm{~cm} \mathrm{H}_{2} \mathrm{O}$. Then, the pressure increased steadily and after $7 \mathrm{~min}$ of pleural pressure monitoring wavered from -50 up to $-25 \mathrm{~cm} \mathrm{H}_{2} \mathrm{O}$ (amplitude $25 \mathrm{~cm}$ $\mathrm{H}_{2} \mathrm{O}$; fig. 2a). The oscillations of the line seen in figure $2 \mathrm{~b}$ reflect the pleural pressure changes during the first measurement cycle presented in figure 2a. The total time for thoracentesis, fluid removal and pleural pressure measurements was approximately $18 \mathrm{~min}$. The procedure was prolonged for approximately $7 \mathrm{~min}$ in order to follow the pleural pressure changes after termination of pleural fluid removal. The total time necessary to perform 6 measurements at different volumes of pleural fluid aspirated was approximately $320 \mathrm{~s}$ (excluding the long-lasting measurement after removal of the last portion of pleural fluid). No complications related to the measurement were noted.

\section{Discussion}

The results of our study show that in the face of the paucity of commercially available pleural manometers, it is possible to build a self-made, electronic device which accurately measures pleural pressure. Only widely accessible elements were used to construct our pleural manometer, e.g. easily available pressure transducers used for blood pressure measurement and a PC with very moderate requirements. Thus, we believe it is also possible to construct a similar device or use our manometer also in other centers.

As further use of our new electronic pleural manometer largely depends on measurement accuracy, the evaluation of the reliability of measurements was the most important part of our study. We found that the pressure measurement accuracy of our electronic manometer is at least as good as that of a water manometer. Comparative analysis of the pleural pressure values measured with our electronic device and a water manometer shows excellent agreement of these two methods. Use of only laboratory 


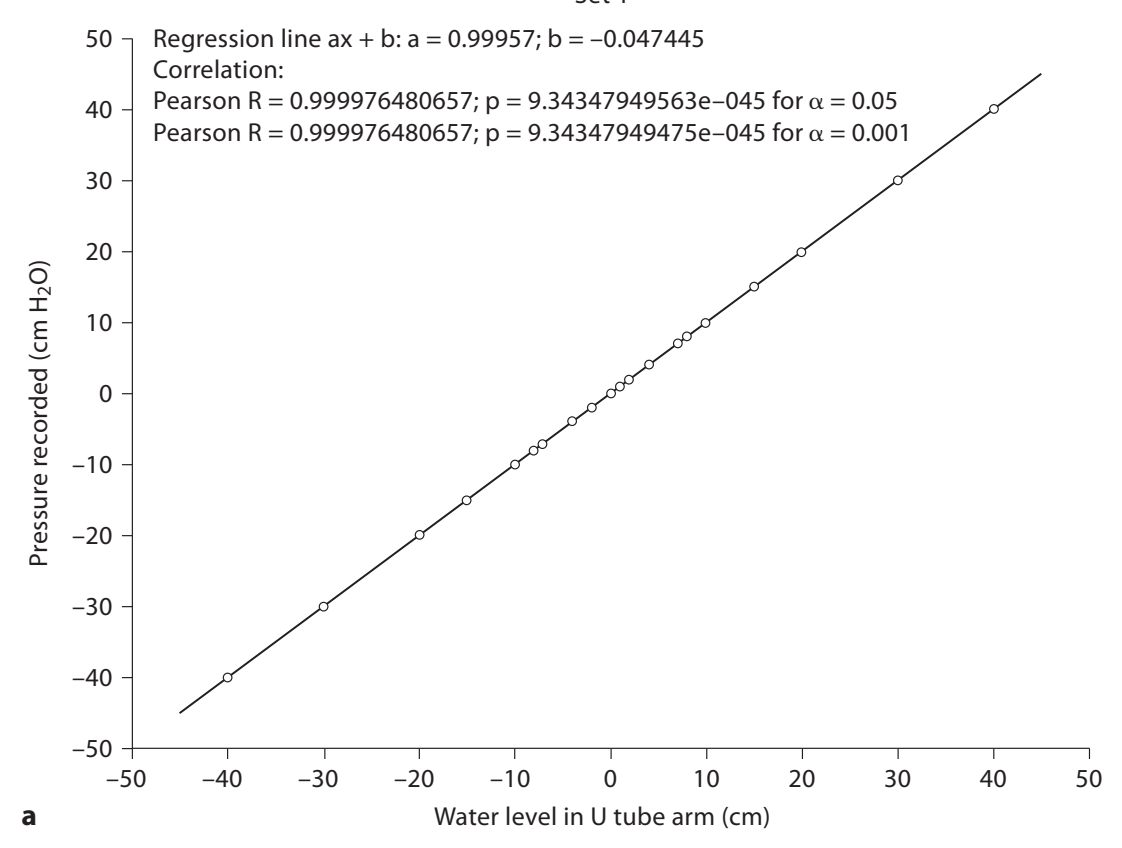

Fig. 3. a Regression line for measurement set 1 . b Bland-Altman plot for measurement set 1 . d.f. $=$ Degrees of freedom.

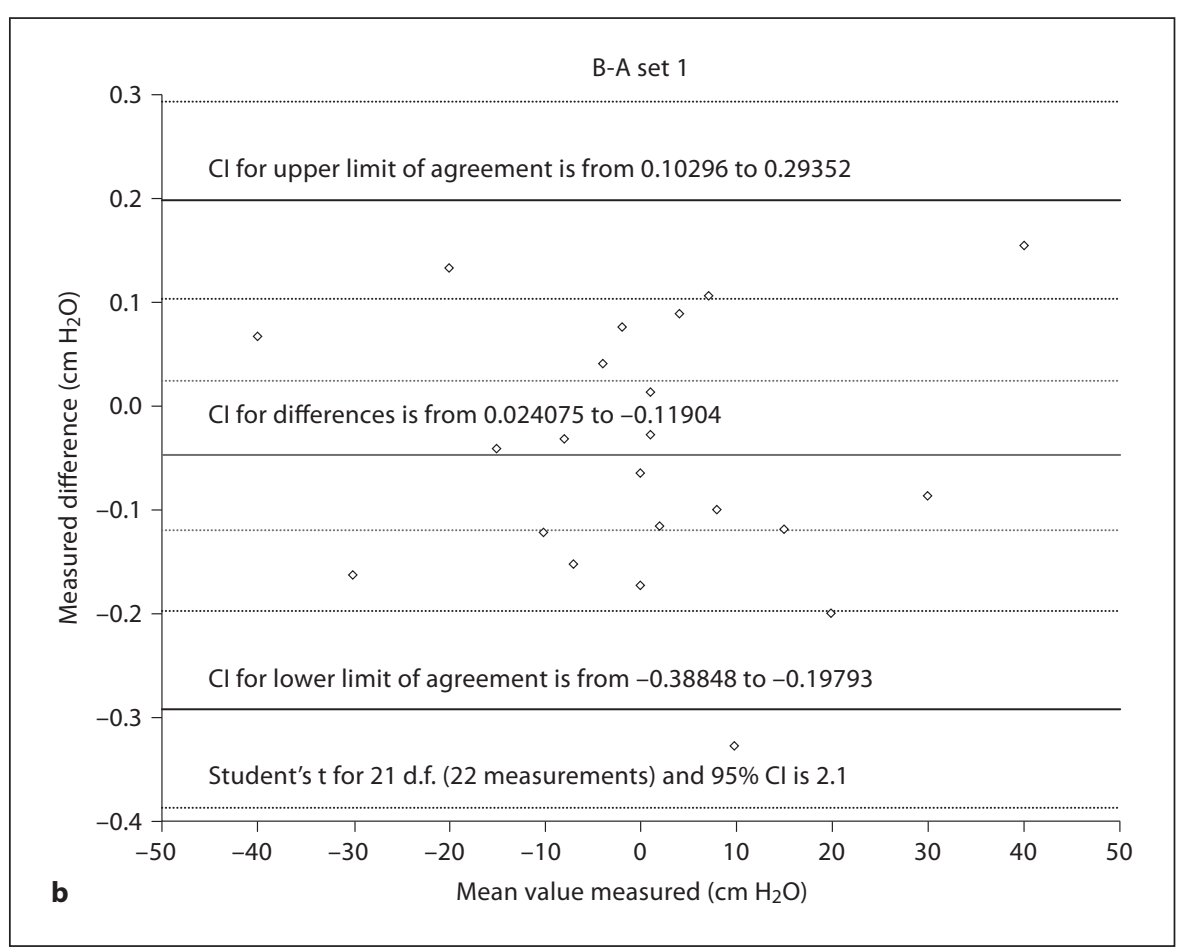

equipment without involvement of any biological elements probably helped to obtain such precise and reproducible results of our experiment. In most earlier studies, water manometers were used alone $[4,5,8]$ or as standard for calibration of other manometric devices $[6,14]$. We found only one study, performed by Doelken et al. [14], which compared overdamped water manometer and electronic device measurements. It showed a very good positive correlation $(\mathrm{r}=0.97 ; \mathrm{p}<0.001)$. The important advantage of that study is its clinical setting. Basing on 
the results of this study, overdamped water and electronic manometers were used simultaneously or only one manometric method was used in subsequent studies [7, 17]. Regarding that point, our comparison of measurements performed by both electronic and water manometers seems to play an important part in our study providing evidence for the proper functioning of the newly developed measurement set.

In our opinion, our electronic manometer has several advantages over the pleural manometers used in other studies. Earlier studies mainly involved different types of water manometers. Water properties as well as technical aspects of a water manometer (such as the length and radius of the tube) result in delayed fluid level stabilization (subsequent to the change in pleural pressure). On the other hand, fluid level changes with the respiratory cycle, and this makes precise assessment of inspiratory/expiratory pressure difficult. The mean pressure is calculated as a sum of end-inspiratory and end-expiratory pressure divided by 2 , as described by Light et al. [4]. Doelken et al. [14] proposed a modification of that system, which is known as overdamped manometer. Introduction of a 22 -gauge needle as a resistor damps fluid column oscillation and allows direct reading of the mean pleural pressure [14]. However, under some circumstances, precise measurement of the intrapleural pressure throughout the whole respiratory cycle may be necessary. Moreover, using both, under- and overdamped water manometers, the pleural pressure reading can be significantly affected by abrupt pressure changes, e.g. during cough. Electronic manometers are deprived of these drawbacks. Very low inertia and the high frequency of measurements, a characteristic of electronic manometers, result in precise measurements even during cough or sighs, as well as directly before and after these maneuvers.

Our pleural manometer also shows some advantages in comparison to electronic manometers dedicated for blood pressure measurements. The pressure values of our device are displayed in $\mathrm{cm} \mathrm{H}_{2} \mathrm{O}$, so converting data from

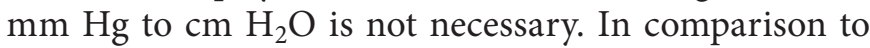
pressure transducers connected to monitors in the intensive care unit, as mentioned by Doelken et al. [14] and Feller-Kopman [16], no special calibration of our manometer is needed except for pressing a calibration button for $5 \mathrm{~s}$ before the first measurement. We believe these are important features of our device, which make the procedure of pleural pressure measurement simple and not time-consuming. It should also be stressed that our new electronic manometer is small, portable and has double power supply; thus, it is possible to perform the procedure in different settings even without access to current supply. We would like to emphasize that albeit a laptop was used in our study to store data, its use to monitor intrapleural pressure is not necessary. The value of this pressure can be simply followed on the numerical display, which is an integral part of the manometer. Connection of the device with a larger display or small monitor, memory and a processor supervising the data acquisition in one box is considered for future versions of the system.

As we did not evaluate the role of pleural pressure measurements in patients with various pleural diseases, we were not able to fully authenticate the usefulness of these pleural pressure measurements. However, some earlier studies reported that pleural manometry can increase the safety of large-volume thoracentesis [4-6], help to recognize trapped lung $[4,5,7]$ and predict the outcome of pleurodesis [8]. There might be other clinical and research applications of pleural pressure measurement. For example, Froudarakis et al. [18] have recently shown that respiratory muscle strength and lung function can be temporarily impaired after medical thoracoscopy. According to our studies, pleural pressure measurements before and after the procedure may add new information on the mechanisms of this phenomenon.

In the clinical part of our experiment, pleural pressure measurement during therapeutic thoracentesis was easy to perform and, in one of our patients, added $<6$ (additional) $\mathrm{min}$ to a procedure lasting $18 \mathrm{~min}$. Since the long-lasting measurement of pleural pressure after the completion of pleural fluid removal was undertaken only for research purposes, we did not add this time to the total procedure time. It should also be stressed that due to measurement quality assessment, every single measurement time was relatively long (45-75 s). We believe that it can be significantly decreased (to $10-15 \mathrm{~s}$ ), but this requires further clinical evaluation. Feller-Kopman et al. [6] found that the measurement of pleural pressure during a large-volume thoracentesis adds $5-10 \mathrm{~min}$ to the procedure. Similar results were reported earlier by Doelken et al. [14]. These authors demonstrated that the time necessary to perform a single measurement of pleural pressure with the overdamped manometer is approximately $1 \mathrm{~min}$ (the first $30 \mathrm{~s}$ are necessary to obtain a stabilization of pleural liquid pressure) [15]. The total time of pleural pressure measurements largely depends on the number of measurements performed during a therapeutic thoracentesis. No special training is necessary for pleural manometer operation, and this seems to be of great importance considering its use in clinical practice. 
In our opinion, the total cost of constructing our electronic pleural manometer is relatively modest. As the cost of the workload may significantly vary in different world regions, only the number of man-hours was presented in our report. The total cost of workload can be easily calculated by multiplication of 80 man-hours and the average cost of 1 man-hour. In our country, the cost of workload was approximately 2.5 -fold higher than the cost of all electronic components. Thus, the total cost of constructing our electronic manometer was $<2,000$ EUR (plus PC with minimal requirements).

We are aware of some limitations of our study. The measurements were performed mainly in laboratory settings. The bias of the results should be taken into account due to the single-blind design of the study. The number of samples and series of measurements performed is not very large but, on the other hand, a very high agreement between the results of electronic and manual measurements was found in each series. Since the clinical part of our study included intrapleural pressure measurement in only 7 patients ( 6 of them having malignant pleural effusion), we were not able to fully assess and discuss the usefulness and limitations of pleural pressure measurement.
However, the study design was a consequence of the main aims of our study which were focused on building a new electronic manometer and evaluation of the accuracy of pleural pressure measurements. The results presented above warrant further studies in different clinical settings.

\section{Conclusions}

The results of our study showed that an electronic pleural manometer can be easily constructed using widely available electronic components and software. The new device reliably measures positive as well as negative instantaneous pressure in the laboratory setting and is easy to use during routine thoracentesis and pleural fluid removal. Our set for intrapleural pressure measurements can measure, display and store values of hydrostatic pressure, avoiding limitations typical for water manometers. We believe similar manometers can be easily built in other centers interested in pleural pressure measurement. The total cost of the device is reasonable and did not exceed 2,000 EUR.

\section{References}

1 Jacobs J: Manometry in the conduct of artificial pneumothorax. Chest 1937;3:18-26.

2 Brandt HJ, Loddenkemper R, Mai J: Atlas der diagnostischen Thorakoskopie. Stuttgart, Thieme, 1983.

-3 Faurschou P, Viskum K: Artificial pneumothorax by the Veress cannula: efficacy and safety. Respir Med 1997;91:402-405.

4 Light RW, Jenkinson SG, Minh VD, George RB: Observations on pleural fluid pressures as fluid is withdrawn during thoracentesis. Am Rev Respir Dis 1980;121:799-804.

5 Villena V, López-Encuentra A, Pozo F, DePablo A, Martín-Escribano P: Measurement of pleural pressure during therapeutic thoracentesis. Am J Respir Crit Care Med 2000; 162:1534-1538.

-6 Feller-Kopman D, Berkowitz D, Boiselle P, Ernst A: Large-volume thoracentesis and the risk of reexpansion pulmonary edema. Ann Thorac Surg 2007;84:1656-1662.

-7 Huggins JT, Sahn SA, Heidecker J, Ravene JG, Doelken P: Characteristics of trapped lung. Pleural fluid analysis, manometry, and air-contrast chest CT. Chest 2007;131:206213.
-8 Lan RS, Lo SK, Chuang ML, Yang CT, Tsao TC, Lee CH: Elastance of the pleural space: a predictor for the outcome of pleurodesis in patients with malignant pleural effusion. Ann Intern Med 1997;126:768-774.

-9 Spencer J: A place for aspiration in the treatment of spontaneous pneumothorax. Tho$\operatorname{rax} 1985 ; 40: 66-67$.

10 Herrejon A, Inchaurraga I, Vivas C, Custardoy J, Marin J: Initial pleural pressure measurement in spontaneous pneumothorax. Lung 2000;178:309-316.

11 Froudarakis MR, Noppen M: Medical thoracoscopy: new tricks for an old trade. Respiration 2009;78:373-374.

12 Froudarakis ME: New challenges in medical thoracoscopy. Respiration 2011;82:197-200.

13 Janssen JP, Collier G, Astoul P, Tassi GF, Noppen M, Rodriguez-Panadero F, Loddenkemper R, Herth FJ, Gasparini S, Marquette $\mathrm{CH}$, Becke B, Froudarakis ME, Driesen P, Bolliger CT, Tschopp JM: Safety of pleurodesis with talc poudrage in malignant pleural effusion: a prospective cohort study. Lancet 2007;369:1535-1539.
14 Doelken P, Huggins JT, Pastis NJ, Sahn SA: Pleural manometry: technique and clinical implications. Chest 2004;126:1764-1769.

15 Huggins JT, Doelken P: Pleural manometry. Clin Chest Med 2006;27:229-240.

16 Feller-Kopman D: Therapeutic thoracentesis: the role of ultrasound and pleural manometry. Curr Opin Pulm Med 2007;13:312_ 318.

17 Heidecker J, Huggins JT, Sahn SA, Doelken P: Pathophysiology of pneumothorax following ultrasound-guided thoracentesis. Chest 2006;130:1173-1184.

- 18 Froudarakis ME, Pataka A, Makris D, Kouliatsis G, Anevlavis S, Sotiriou I, Steiropoulos P, Eleftheriadis S, Bouros D: Respiratory muscle strength and lung function in patients undergoing medical thoracoscopy. Respiration 2010;80:220-227. 